\title{
Empreendedorismo feminino: desafios e oportunidades no cenário turístico de Campo Grande, Mato Grosso do Sul
}

\section{Female entrepreneurship: challenges and opportunities in the tourism scenario of Campo Grande, Mato Grosso do Sul}

\section{Marta Regina da Silva Melo}

Doutoranda em Meio Ambiente e Desenvolvimento Regional pela Universidade para o Desenvolvimento do Estado e da Região do Pantanal - Uniderp, Campo Grande/MS, Brasil Email: martamelors@gmail.com

Djanires Lageano Neto de Jesus

Professor efetivo da Universidade Estadual do Mato Grosso do Sul - UEMS, Campo Grande/MS, Brasil

E-mail: netoms@uems.br 


\section{RESUMO}

Atividades turísticas abrangem diversas áreas transversais da cadeia produtiva, ao passo que o empreendedorismo feminino pode ser considerado uma tendência que se caracteriza pelo crescimento acelerado em todo o mundo. $\mathrm{O}$ presente estudo tem como objetivo analisar a atuação da mulher empreendedora no setor de turismo e a contribuição para o desenvolvimento em Campo Grande, Mato Grosso do Sul. O método utilizado foi baseado na análise de conteúdo de Bardin, a partir de duas amostras compostas pelo público feminino atuante no contexto empreendedor da Associação de Mulheres de Negócios e Profissionais de Campo Grande (BPW-CG); e com mulheres empreendedoras que atuam no setor de turismo local. Os resultados da pesquisa indicaram que a representatividade das mulheres empreendedoras no setor de turismo busca atenuar os problemas resultantes da inconsistência do desenvolvimento das atividades turísticas. Além disso, constatou-se que $48,57 \%$ das mulheres empreendedoras apresentaram nível superior completo, em acordo com os dados apresentados pelo IBGE e o SEBRAE, no qual é relatado o crescimento do nível educacional das mulheres empreendedoras. Portanto, empreender no setor de turismo vai além de uma visão mercadológica e está associado à capacidade de envolver pessoas e, sobretudo, devido ao dinamismo feminino que enriquece e diversifica o campo do empreendedorismo.

Palavras-chave: Mulheres Empreendedoras. Gestão de Negócios. Turismo.

Desenvolvimento.

\section{ABSTRACT}

Tourist activities include various cross-sectional areas of by the supply chain, while female entrepreneurship can be considered a trend characterized by accelerated growth worldwide. This study aims to analyze the performance of entrepreneurial women in the tourism sector and the contribution to the development in Campo Grande, Mato Grosso do Sul. The method used was based on the analysis of Bardin's content, from two samples composed of women who work in the entrepreneur context of Business and Professional Women from Campo Grande (BPW-CG); and with women entrepreneurs who work in the local tourism sector. The survey results indicated that the representation of women entrepreneurs in the tourism sector seeks to minimize the problems resulting from the inconsistency of the development of tourist activities. In addition, it was noted that $48.57 \%$ of women entrepreneurs presented full top level, according to the data presented by IBGE and SEBRAE, who reported the growth of the educational level of women entrepreneurs. So, undertake at the tourism sector goes beyond a market vision and is associated with the ability to involve people and, above all, due to the feminine dynamism that enriches and diversifies the field of entrepreneurship.

Keyword: Entrepreneurial Women. Business Management. Tourism. Development. 


\section{INTRODUÇÃO}

A busca constante da mulher por novos desafios torna o empreendedorismo feminino uma temática que desperta natural interesse de estudo (Gouvêa; Silveira \& Machado, 2013). Contudo, a importância da mulher empreendedora no setor de turismo é abordada com pouco interesse (Ateljevic \& Page, 2011), e desta forma denota que o empreendedorismo no setor de turismo é pouco evidenciado.

Embora as estatísticas relacionadas ao empreendedorismo feminino pareçam encorajadoras, empreender no setor de turismo, para as mulheres, não vem sendo uma tarefa fácil (Bomfim \& Teixeira, 2015). Assim, é identificada a necessidade de apoio para a inserção da mulher no mercado do turismo, apta a assumir esse desafio.

O Mato Grosso do Sul faz divisa com os estados de Goiás, Mato Grosso, Minas Gerais, Paraná e São Paulo; e fronteira com os países da Bolívia e Paraguai. Por ter uma localização estratégica, é um importante polo de desenvolvimento econômico, cultural e social.

A capital, Campo Grande, foi planejada em meio a uma vasta área verde, com ruas e avenidas largas e com diversos jardins por entre as suas vias. É uma das cidades mais arborizadas do Brasil, onde 96,3\% das casas contam com a sombra de um arvoredo (Censo do Entorno do IBGE, 2010). Dispõe de uma estrutura turística básica e de equipamentos de lazer presentes em espaços públicos, com vocação para os segmentos das atividades de turismo em eventos e negócios.

Por essas características, Campo Grande apresenta-se como um munícipio favorável para a atuação das mulheres no empreendedorismo feminino destinado ao setor de turismo. A pesquisa destaca a atuação da mulher nas atividades turísticas de Campo Grande e a compreensão das habilidades, oportunidades, realizações e os desafios do empreendedorismo feminino, enquanto elos que compõem o produto turístico.

O presente estudo tem como objetivo analisar a atuação da mulher empreendedora no setor de turismo em Campo Grande - MS e sua contribuição para o desenvolvimento local.

\section{REFERENCIAL TEÓRICO}

\subsection{Turismo e empreendedorismo}

O turismo é analisado de forma ampla, devido ao seu potencial que envolve diversos segmentos e, consequentemente, suas especificidades. De acordo com a OMT 
(2001), o conceito de turismo pode ser estudado por diferentes perspectivas, dada à complexidade das relações entre os elementos que o formam.

Para tanto, os efeitos do crescimento do turismo não se dão apenas em níveis econômicos, mas existe toda uma dinâmica de implicações que evidenciam as suas várias dimensões, sejam elas sociais, políticas, culturais e psicológicas (Paiva, 1995).

Embora alguns círculos vejam o turismo apenas como a indústria de viagens e prazer, trata-se de um fenômeno que avança para além das questões comerciais e econômicas (Moesch, 2000). Por este viés ressalta-se que é um setor amplo, cuja pluralidade é indiscutível.

O conceito de empreendedorismo foi elaborado por diferentes áreas do conhecimento, conforme as suas peculiaridades, com aspectos multidisciplinares que harmonizam objetivos comuns ao processo de inovação. Empreendedorismo é um fenômeno baseado na cultura, integrado ao capitalismo e fornece estrutura ao engajamento (Chell, 2011). Entretanto, a disposição em idealizar, coordenar e realizar projetos integram elementos essenciais a esse universo.

Ao analisar o conceito por outras vertentes, foi descrito que empreendedorismo é um catalisador para o crescimento econômico e competitivo do mercado nacional ( GEM, 2010). Em adição, empreendedores geram empregos, dirigem e modelam a inovação e aceleram mudanças estruturais na economia (Melhado; Plaster \& Yoong, 2013). Muitas definições podem ser encontradas para o termo empreendedorismo, mas qualquer uma delas impõe limites à percepção e ao entendimento do assunto, ao levar em conta o seu contexto em um dado momento de tempo, local e espaço (Gomes, 2006). Quando se propõe a percorrer caminhos desconhecidos, é necessário captar e focar informações sobre variáveis positivas e negativas a respeito daquilo que a nova atividade possa oferecer.

\subsection{A mulher na gestão de negócios}

Atitudes empreendedoras fazem parte da evolução histórica do universo feminino. A partir das lutas enfrentadas pelas mulheres desde o final do século XIX, decorreram movimentos feministas organizados (Scott, 1990). Essas ações mobilizaram as mulheres para a realização de greves, especificamente para a melhoria das condições de trabalho e de remunerações adequadas.

Em face dessa trajetória de resistência e conquistas, compreende-se que todos os esforços aplicados foram em prol de uma questão social, na tentativa de suprimir o 
preconceito, na possibilidade de promover a igualdade, dignidade e, em particular, o respeito. Vieira (2005) ressalta que cada época, a seu modo, influencia o sujeito na forma de pensar e de agir. Assim, a atuação da mulher percorre um processo de transformação em diversos aspectos cronológicos. Pode-se dizer que mulher empreendedora é, ao mesmo tempo, singular e histórica (Ferreira \& Nogueira, 2013). Tanto a construção, quanto o reconhecimento da identidade feminina continuam sendo uma tarefa árdua (Maders \& Angelin, 2010). Nesse ínterim, é visível o empenho produzido pelas mulheres ao empreenderem em diversas áreas do conhecimento.

Nesse aspecto, o modo de empreender da mulher brasileira se sobressai no cenário mundial, o que torna o Brasil um dos principais países no qual as mulheres mais empreendem (Nogami, Medeiros \& Faia, 2014). Para viver em um mundo cada vez mais globalizado é necessário encarar os obstáculos e propiciar uma releitura dos fatos, haja vista que toda essa evolução é caracterizada como um fenômeno pelas lutas, conquistas e capacidade de resiliência da mulher.

\subsection{Empreendedorismo feminino e o setor de turismo}

Por meio das estatísticas de gênero, o IBGE (2014) mostra como as mulheres ganharam espaço na realidade socioeconômica do Brasil. Elas têm se escolarizado mais e são maioria entre os universitários, com a taxa de 15,1\%. Consequentemente, o nível educacional das mulheres é maior do que o dos homens na faixa etária de 25 anos ou mais. É notável que a desenvoltura para o empreendedorismo feminino segue e evolui diariamente.

Avançar na compreensão do papel das mulheres no empreendedorismo em turismo é possibilitar uma redefinição do turismo como força dinamizadora, não apenas da economia monetária, como também do capital social (Peeters \& Ateljevic, 2011). Esse avanço se caracteriza como uma evolução no processo empreendedor, em razão das mulheres facultarem um novo rumo para sua própria vida e por favorecem a formatação da história.

O SEBRAE (2014) publicou em uma pesquisa intitulada "Mulher Empreendedora em Mato Grosso do Sul”, que as empreendedoras sul-mato-grossenses representam 103 mil mulheres, em diferentes áreas, que aceitaram o desafio de viverem uma vida empreendedora, seja para trazerem uma renda para a família, ou a fim de alcançarem a tão sonhada realização pessoal. Condizente à pesquisa, as mulheres representam 52,2\% dos empreendedores que iniciam seus negócios no Brasil. No Centro-Oeste este percentual é de 56,5\%; e das empresas consolidadas no mercado, 44\% são geridas por mulheres. A pesquisa aponta para os seguintes 
aspectos: a motivação de estar à frente de uma empresa; as dificuldades encontradas; como as empreendedoras lidam com o tempo; e os segredos para o sucesso.

A capacidade de obter êxito nas ações propostas e o futuro da atividade dependerá das metas, da qualidade e da capacidade dos empreendedores em conduzirem os seus negócios (Ruschmann \& Solha, 2004). Estratégias adotadas podem ser indispensáveis para a antecipação das variáveis positivas e negativas.

Portanto, o empreendedorismo feminino solidifica-se cada vez mais como uma tendência global e influencia as transformações da sociedade. Ser empreendedora não é experimentar apenas uma trajetória de sucesso, é necessário considerar que o percurso explorado possa estar cercado de ônus e bônus, no desenvolver de cada circunstância vivida e a ser vivenciada.

\section{METODOLOGIA}

O estudo foi conduzido em Campo Grande, capital de Mato Grosso do Sul (Figura 1). Sua população estimada é de 863.982 habitantes e possui área territorial de $8.092,951 \mathrm{~km}^{2}$ (IBGE, 2016).

Figura 1. Localização de Campo Grande, capital de Mato Grosso do Sul.

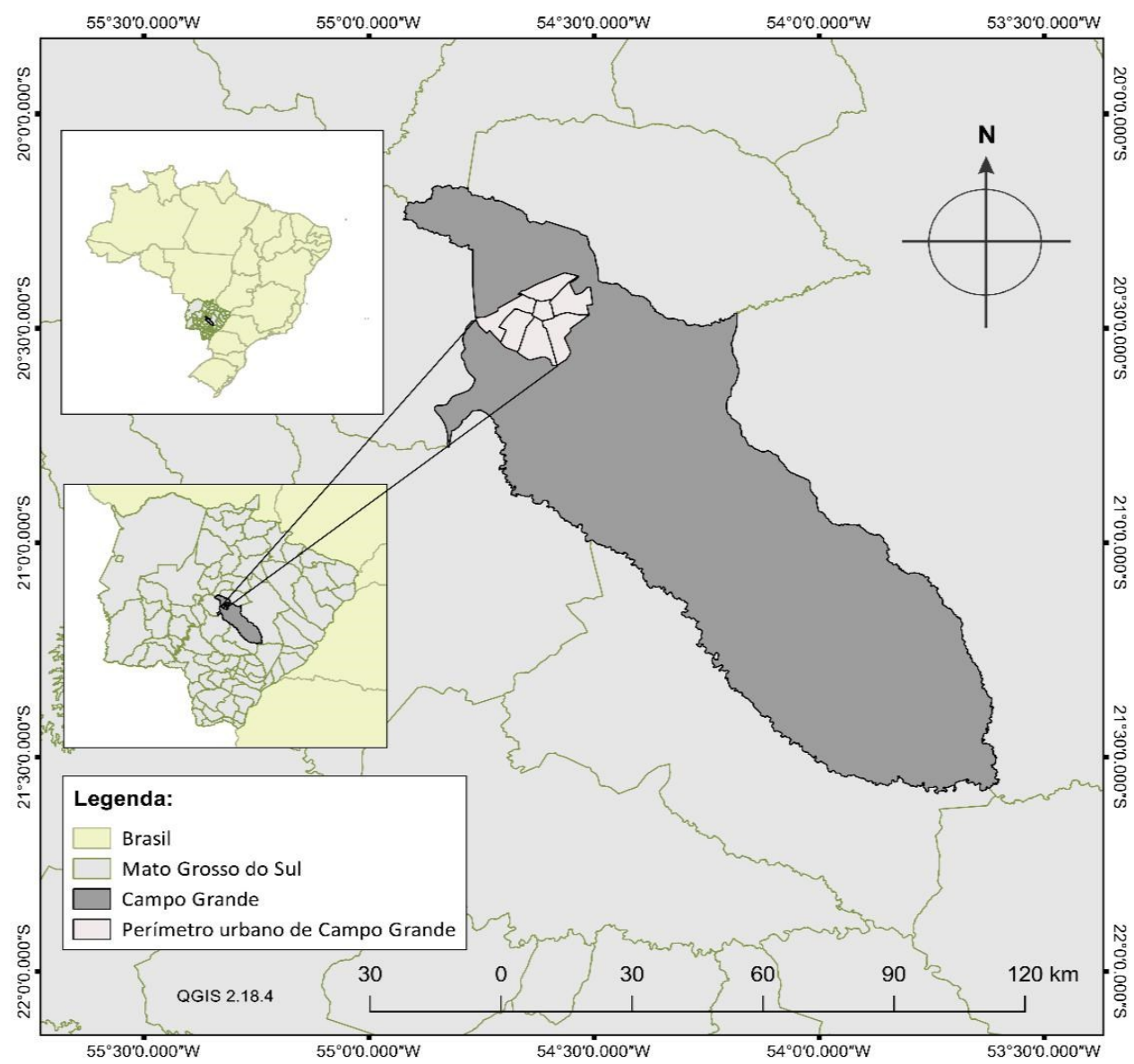


Fonte: Elaborado pelo autor.

A pesquisa foi constituída a partir de uma abordagem qualitativa não probabilista, com base na análise de conteúdo de Bardin (2006). A revisão bibliográfica foi realizada com a finalidade de situar o estudo no contexto geral do conhecimento e fundamentar a pesquisa (Dencker, 2007).

Foi aplicado um questionário para um primeiro grupo investigado, correspondente a uma amostra de 70 mulheres empreendedoras de diferentes setores associadas à Associação das Mulheres de Negócios e Profissionais de Campo Grande (Business Professional Woman - BPW. Para a segunda amostra, composta por cinco empreendedoras atuantes no setor de turismo de Campo Grande, foi aplicada uma entrevista estruturada. Essa técnica é considerada mais adequada para o desenvolvimento de levantamentos sociais (Gil, 2008).

As empreendedoras do segundo grupo investigado foram identificadas pela letra "E", seguida de uma sequência de números de 1 a 5 . O primeiro depoimento destacou os relatos de uma gestora e empreendedora em turismo, representante do setor público (E-1). Em seguida, a apresentação de empreendedoras do setor privado, com ênfase para Hotelaria (E-2); Eventos (E-3); Ecoturismo e Educação Ambiental (E-4); e Agência de Viagens (E-5). O intuito foi descrever a atuação das empreendedoras e apresentar informações de suas experiências como contributo para o desenvolvimento do turismo local.

\section{ANÁLISE E DISCUSSÃO DOS RESULTADOS}

Ao analisar os resultados dos questionários aplicados para a primeira amostra com mulheres associadas à BPW-CG, percebeu que a preferência pelo empreendedorismo se relacionou ao grau de independência e de estabilidade financeira, associados à realização pessoal. Essa indicação é semelhante a estudos gerais sobre o empreendedorismo feminino (Tonelli \& Andreasse, 2013; Sehgal, 2014; Oliveira et al. 2015; Rodrigues, Melo \& Lopes, 2016), nos quais o processo de empoderamento das mulheres produz resultados positivos para as empresas, para a sociedade e para o desenvolvimento do país.

O perfil etário indicou que $10 \%$ das mulheres empreendedoras estão na faixa etária de 18 a 28 anos; $22,86 \%$, com 29 a 39 anos; $51,43 \%$, com 40 a 59 anos; e 15,71\%, com idade acima de 60 anos. A evolução cotidiana de cada pessoa, independentemente da idade, é essencial para o resultado final no processo empreendedor. 
Acerca do grau de formação, as entrevistadas com nível superior obtiveram o maior índice, com 48,57\% (Figura 2). Neste sentido, quanto maior o nível de escolaridade, maior é a atividade empreendedora (Nogami, Medeiros \& Faia, 2014).

Figura 2. Amostra do grau de instrução das mulheres empreendedoras associadas à BPW-CG.

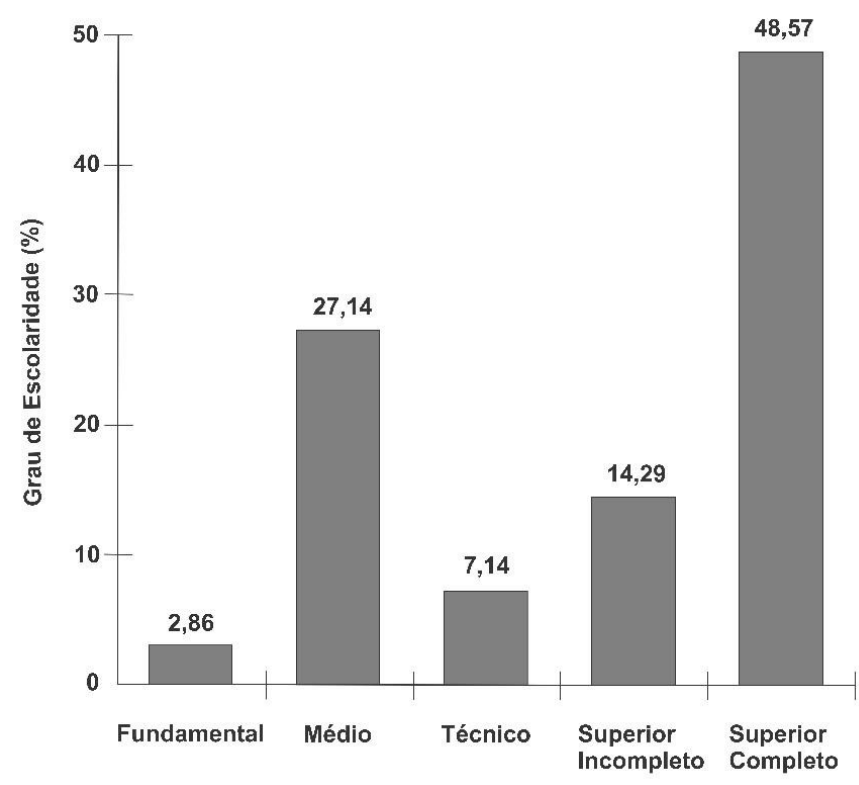

Fonte: dados da pesquisa.

Ao analisar a questão que investigou os setores de atuação das entrevistadas, verificou-se que os setores do Comércio e Serviços foram os que mais despontaram, com $35,71 \%$ e $40 \%$, respectivamente. Com um percentual menor, empreendem nos setores da Indústria e no Turismo 2,86\% (Figura 3).

Figura 3. Amostra dos índices dos setores de atuação das mulheres empreendedoras associadas à BPW -CG.

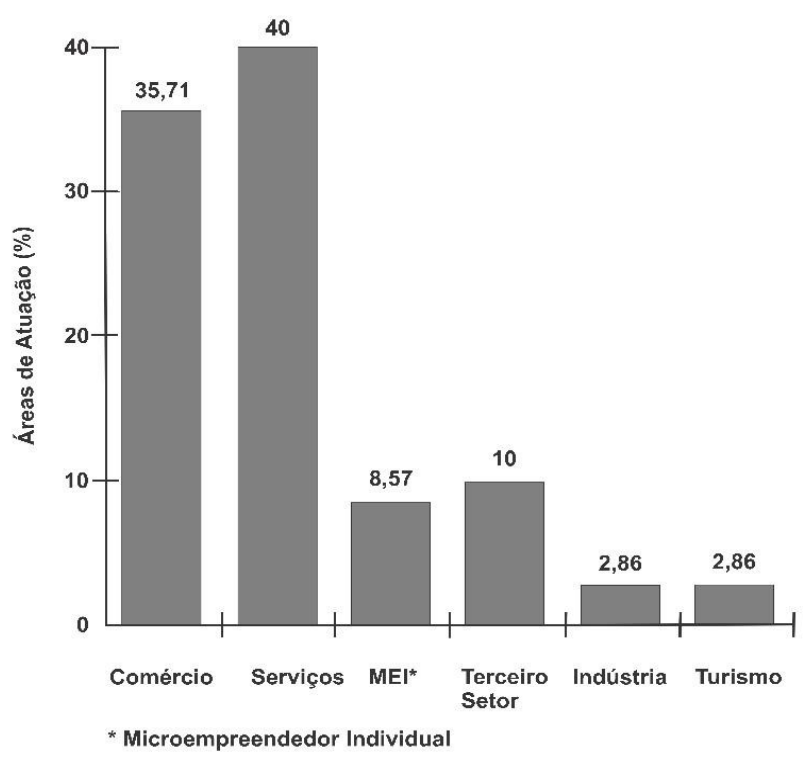

Fonte: dados da pesquisa. 
Ao questionar quais os canais de informação recorrem, com o propósito de alavancar os negócios e obterem sucesso. As empreendedoras relataram que buscam informações de maneiras distintas, mas têm a internet como ferramenta favorita para aquisição da informação (Figura 4).

Figura 4. Canais de acesso a informações utilizadas por uma amostra das mulheres empreendedoras associadas à BPW-CG.

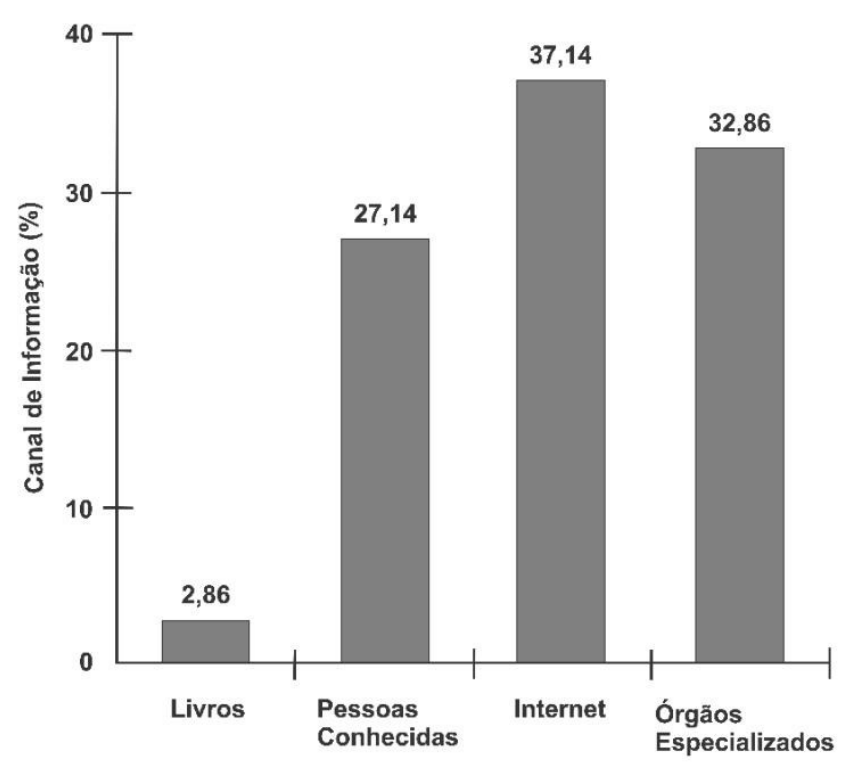

Fonte: dados da pesquisa.

Correspondeu a $37,14 \%$ o percentual de empreendedoras que utilizam a internet como ferramenta favorita para adquirir informações; 32,86\% responderam que recorrem a órgãos especializados; $27,14 \%$ buscam informações com pessoas conhecidas; e 2,86\% utilizam-se de livros para aquisição da informação.

Sempre bem-informada, a mulher de negócios está constantemente em busca de novidades, seja por meio de cursos, congressos, internet, livros, seja por contato com especialistas (SEBRAE, 2014). Em vista destes resultados, o acesso à informação e tecnologias permitem que as pessoas se deparem com as oportunidades e se apropriem delas (Silva, Furtado \& Zanini, 2015). Na concepção de que o conhecimento é uma consequência produzida pela informação, pode-se dizer que é um dos principais instrumentos para o desenvolvimento pessoal.

Concernente ao questionamento relativo à motivação em empreender, 67,14\% relataram que foi por oportunidade e $32,86 \%$ por necessidade, consoante com os dados divulgados no estudo de Nogami, Medeiros e Faia (2014), em que o empreendedorismo por 
oportunidade foi maior em relação ao induzido pela necessidade. Um empreendedor é o detentor da capacidade de reinventar os meios para atender às crescentes necessidades da sociedade e proporcionar grandes transformações, tanto econômicas como sociais e até mesmo ambientais (Amorim \& Batista, 2012).

O item com referência ao planejamento no empreendimento apresentou que 57,14\% das empreendedoras possuíam algum tipo de planejamento; e 42,86\% não possui nenhum planejamento para suas ações. Segundo Hisrich; Peters e Shepherd, (2014), há uma tendência entre muitos empreendedores, no sentido de evitar o planejamento, e justificam que o planejamento é entediante ou desinteressante. O planejamento é uma etapa importante de qualquer operação empresarial (Hisrich; Peters \& Shepherd, 2014), indispensável para obter sucesso em qualquer empreendimento.

$\mathrm{Na}$ sequência, são apresentados os resultados da segunda amostra da pesquisa. $\mathrm{O}$ primeiro depoimento destacou os relatos de uma gestora e empreendedora em turismo, considerada uma representatividade do setor público. Os depoimentos seguintes dizem respeito às empreendedoras do setor privado. Buscou-se a clareza dos diversos elos de atividades que integram a cadeia de turismo e que correspondem ao produto turístico. Desse modo, ao sistematizar os dados, foram enunciadas temáticas que se unem à totalidade da compreensão a respeito da atuação da mulher empreendedora no setor de turismo em Campo Grande, MS.

\subsection{Os desafios das empreendedoras no setor de turismo em Campo Grande}

Inicialmente foi questionado quais os principais desafios e oportunidades em empreender nas atividades turísticas em Campo Grande? A entrevistada do setor público respondeu:

Tendo em vista que o segmento de eventos e negócios são os mais promissores, pela estrutura de equipamentos que apresentam, pode-se dizer que o grande desafio é diversificar os demais segmentos turísticos (E-1).

A integração da mulher com a prática do empreendedorismo no setor do turismo local ainda está em fase de construção, pois os demais segmentos do turismo precisam ser conhecidos e reconhecidos com maior relevância na capital, em atenção às peculiaridades que cada segmento apresenta.

Ao responderem o mesmo questionamento, as entrevistadas do setor privado mencionaram que: 
O maior desafio de se empreender no setor turístico em Campo Grande é justamente o volume de turistas. É necessário captar eventos e criar atrativos turísticos, para gerar demanda e atender não somente os hotéis, mas toda a cadeia produtiva do turismo (E-2).

No setor de eventos, o principal desafio para empreender reside na inexistência de estrutura física (E-3).

O maior desafio é empreender diante da ausência de políticas públicas que reconheçam e incentivem a valorização dos inúmeros atrativos turísticos da cidade, principalmente no que diz respeito ao turismo de vida silvestre, um potencial incrível que deve ser reconhecido e valorizado (E-4).

Cada empreendedora fez considerações relacionadas à área de atuação e reivindicaram desempenho das políticas públicas para o setor de turismo em Campo Grande, o que conjuga com o estudo realizado por Nogami, Medeiros e Faia (2014), no qual as políticas governamentais são consideradas como fatores limitantes do empreendedorismo.

Campo Grande é uma capital pouco explorada turisticamente, por isso precisa de empreendedores inovadores que queiram criar oportunidades de negócios (E-5).

Para a entrevistada E-5, o principal desafio é a participação de empreendedores com uma visão inovadora e com atenção na dinâmica do mercado consumidor.

\subsection{A contribuição e o desenvolvimento local}

Com a proposta de obter relatos sobre os reflexos de contribuição de cada empreendedora para o desenvolvimento local, as entrevistadas argumentaram o seguinte:

A maior contribuição é fazer com que o turismo seja reconhecido como atividade econômica que gere emprego e desenvolvimento, com o envolvimento da comunidade (E-1).

É possível identificar a expectativa da entrevistada em promover a inclusão do turismo como fator positivo para o desenvolvimento local.

Para hotelaria, a contribuição é a de prestação de serviços para a cidade (E-2).

Os eventos, como um todo, movimentam o mercado local. Por isso é importante acompanhar as mudanças e propiciar melhorias nos serviços prestados (E-3).

As contribuições são voltadas para orientações no turismo de base comunitária; roteiros de turismo sobre duas rodas (bicicletas), com vistas à contemplação da vida silvestre em áreas verdes da cidade; e formação de condutores de visitantes nas Unidade de Conservação da natureza (E-4).

O desafio maior é o da contribuição diária em convencer os visitantes e os próprios moradores de que Campo Grande é uma cidade fantástica, agradável, segura e com entretenimento, o que faz dela um excelente destino de eventos (E-5). 
A postura da mulher frente aos desafios está em cada sonho buscado, em cada objetivo alcançado, em cada conflito vivido e superado, está no produto final que seu projeto resultou (Rodrigues, Melo \& Lopes, 2016). Por isso, é fundamental que as mulheres empreendedoras no setor de turismo possam perseverar no uso de mecanismos e estratégias no sentido de obterem melhorias em suas áreas de atuação.

\subsection{A motivação para empreender}

O que as motivaram a empreenderem no setor de turismo, responderam:

Enxergar o turismo como uma mola propulsora de desenvolvimento local, geração de renda e inclusão social (E-1).

O que motivou a dar continuidade ao empreendimento foi o de ser um hotel respeitado, premiado dentro do mercado local (E-2).

A motivação para empreender no setor de turismo foi a vocação (E-3).

A possibilidade de formar novos agentes de conservação, tendo como princípio a Educação Ambiental conectada ao turismo (E-4).

Empreender no turismo é completamente diferente de ser turista. A motivação como turista para entrar no mercado de turismo foi essencial, pelo prazer de bem receber as pessoas (E-5).

As motivações apresentadas constituem ações que vão além de um processo que relaciona desejo e necessidade para o desempenho no setor turístico.

As empreendedoras expuseram informações sobre suas motivações e características peculiares e as utilizaram para argumentar sobre o desenvolvimento local. Seja qual for sua razão, motivação ou necessidade o empreendedorismo tem dado à sociedade e para a mulher caminhos de sucesso (Amorim \& Batista, 2012).

\subsection{O setor de turismo}

Ao investigar quais os principais motivos que apontam mulheres empreendedoras representarem o mercado de turismo em Campo Grande, comentaram o seguinte:

Por ser uma atividade não convencional e que aglomera vários setores, a natureza feminina tem a característica de organizar e executar, para que tudo funcione. Por isto, é natural que a presença da mulher cresça no mercado turístico (E-1).

No turismo, cada vez mais são observados hotéis administrados por mulheres. Aos poucos, as mulheres inserem-se no mercado com mais qualificação e profissionalismo (E-2).

A mulher se destaca em diversas frentes, assim como em empreendimentos de turismo na cidade. A garra, a perseverança, visão de futuro e a conquista do novo 
são alguns dos requisitos que indicam as mulheres como grandes alavancas do turismo (E-4).

Existem muitas mulheres que trabalham no turismo com rotinas fixas. Mas, para empreender neste mercado tem que se fazer escolhas e contar com um apoio familiar muito sólido (E-5).

Os incentivos vão desde o âmbito econômico, à tomada de decisões, integradas ao bem-estar das relações. Vale ressaltar que o empoderamento da mulher além de alterar o sistema no mercado de trabalho, tem impactado significativamente as relações familiares (Oliveira et al. 2015).

Não há conhecimento de base de informações em relação ao perfil dos proprietários
das empresas do setor de turismo em Campo Grande e não se percebe um número
significativo de mulheres atuantes (E-3).

A respondente E-3 não explicou claramente o questionamento e alegou que não percebe um número significativo de mulheres empreendedoras no setor de turismo em Campo Grande. Apesar disso, cada empreendedora assinalou informações que possibilitaram a visibilidade sobre a força de vontade e disposição em impulsionarem o turismo local.

\subsection{As instituições e seu papel no empreendedorismo}

Foi questionado sobre a existência de instituições de apoio que se identificam como centro especializado na área de empreendedorismo para o setor de turismo. Alegaram que:

Instituições do sistema "S", por oferecerem cursos de aperfeiçoamento e capacitações; as Universidades, que formam os profissionais para o setor; e as entidades do trade turístico, que buscam aperfeiçoar e qualificar seus associados e parceiros para atenderem às necessidades do segmento (E-1).

No depoimento da gestora do setor público, as ações estão sendo desenvolvidas com o propósito de fomentar o setor turístico. Também mencionou que muito precisa ser feito em favor da integração e promoção dos diversos segmentos turísticos na capital.

Sobre instituições que promovam informações para empreenderem no setor de turismo, foi apontado pelas demais entrevistadas que:

Campo Grande não possui nenhuma instituição de ponta, especializada no turismo. Caso fosse recomendar, o SEBRAE/MS poderia ser uma saída, devido aos cursos empresariais oferecidos (E-2).

$\mathrm{Na}$ área de eventos não existe nenhuma instituição que contribui efetivamente para a melhoria do setor (E-3).

Não há conhecimento de instituição em Campo Grande com esse foco. Trabalhar com o turismo permite conhecer muitas pessoas, trocar experiências, o que alimenta a veia empreendedora (E-5). 
O Instituto Mamede de Pesquisa Ambiental e Ecoturismo, empresa sediada em Campo Grande - MS, como instituição que fomenta e desenvolve o empreendedorismo para o turismo sustentável (E-4).

De modo geral, foi conferida homogeneidade nos argumentos das empreendedoras do setor privado, ao sinalizarem a falta de uma instituição promotora de informações e propostas para empreender no setor de turismo.

Em vista disso, destaca-se a criatividade brasileira em buscar alternativas de sobrevivência e a flexibilidade no enfrentamento das dificuldades de um clima econômico incerto (Natividade, 2009), bem como a atuação em consequência da falta de instituições no apoio para empreender no setor de turismo.

Ao longo das declarações foi esclarecido que a representação das mulheres empreendedoras nos diferentes segmentos busca atenuar os problemas advindos das incongruências do desenvolvimento do setor de turismo na capital. O setor de turismo é um dos maiores geradores de riqueza e emprego do mundo, oferece às mulheres quase o dobro de oportunidades de se tornarem empresárias (UNWTO, 2010). Por isso, é necessário ampliar e aprofundar as parcerias entre o setor público, o privado e a sociedade civil, na busca de desenvolver produtos e serviços a partir de uma concepção global dos interesses da cidade (Gastal \& Moesch, 2007).

As entrevistadas dispõem de características similares, como o comprometimento, a iniciativa, a persistência e a autoconfiança, às quais revelam como mulheres empreendedoras de sucesso. A dedicação, a coragem e a autodeterminação fazem referência ao fator subjetivo, no qual a estrutura psicológica pode ser determinante para uma gestão criativa e vitoriosa (Rodrigues, Melo \& Lopes, 2016).

Ao utilizar diversos estudos sobre empreendedorismo feminino, as discussões associadas a esse fenômeno indicam similaridades por parte do diagnóstico dos autores. Por essa razão, Gomes (2006) destaca que as características empreendedoras podem variar em função da atividade que o empreendedor executa em uma dada época ou de acordo com a fase de crescimento da empresa ou até por conta da localização ou região da realidade em estudo. Ferreira e Nogueira (2013) mencionam que cada trajetória confere um caráter totalmente singular à atividade desenvolvida pelas empreendedoras que se posicionam ativamente frente às situações relativas aos negócios.

Logo, o empreendedorismo feminino enriquece e diversifica o campo do empreendedorismo com um crescimento econômico mais sustentável (Nissan; Carrasco \& Castaño, 2012). Sendo assim, empreender no setor de turismo vai além de uma visão 
mercadológica e pode estar associado à capacidade de envolver pessoas e fazê-las atentaremse às questões de inclusão nos aspectos sociais, ambientais e econômicos.

\section{CONSIDERAÇÕES FINAIS}

Em razão do que se pretendeu investigar, foi possível apresentar informações da atuação das empreendedoras e de suas experiências como contributo para o desenvolvimento do turismo local. As mulheres que empreendem nas atividades de turismo de Campo Grande destacaram que este setor se encontra em amplo crescimento. Todavia, os desafios precisam ser superados.

Diante das discussões e segundo as entrevistadas, não existe claramente uma instituição especializada que possa avaliar e apoiar um modelo de negócio e que ofereça sugestões para empreender na área do turismo. Ainda que haja espaços que possam fomentar o empreendedorismo com foco no turismo, dentre os quais citam-se: a Casa do Turismo; SEBRAE; SESC; Instituições de Ensino Superior; e a própria BPW-CG. Infere-se que, ao reunirem esforços, poderiam promover orientações por meio de cursos e capacitações para o empreendedorismo no setor de turismo.

Persiste certa fragilidade no tocante à divulgação de dados estatísticos e indicadores sobre a atuação da mulher empreendedora no setor turístico de Campo Grande. Neste aspecto, sugere-se que os gestores administrativos das esferas estaduais e municipais dos órgãos de Turismo possibilitem a criação de um espaço voltado para a promoção de orientações vocacionais direcionadas ao setor de turismo. Também, conte com parcerias estratégicas, haja vista a necessidade em seguir as tendências de mercado. Além disso, deve-se considerar a mudança do perfil do consumidor, cada vez mais conectado e mais exigente.

Embora insista a desigualdade entre gêneros, a mulher conquista espaços de forma eficaz e pode contribuir de forma significativa com o desenvolvimento do setor turístico em qualquer região do país. Para tanto, a mulher empreendedora deve deixar a sua essência conduzir os seus passos, pois o empoderamento feminino é uma das maiores ferramentas para a transformação de uma sociedade menos conservadora.

Espera-se que as contribuições apresentadas neste estudo possam se desdobrar em novas pesquisas sobre o empreendedorismo feminino e para outros segmentos das atividades turísticas. 


\section{REFERÊNCIAS}

Amorim, R. O. \& Batista, L. E. (2012). Empreendedorismo feminino: razão do empreendimento. Pitágoras, 3(3), 1-3.

Ateljevic, J. \& Page, S. (2011). Introdução. In: Ateljevic, J, Page, S. J, Almeida, M. V. (Org.). Turismo e empreendedorismo, p. 12-17. Rio de Janeiro: Elsevier.

Bardin, L. (2011). Análise de Conteúdo. Lisboa. Edições 70.

Bomfim, L. C. S. \& Teixeira, R. M. (2015). Empreendedorismo Feminino: desafios Enfrentados por Empreendedoras na Gestão de Pequenos Negócios no Setor de Turismo. Revista Pensamento Contemporâneo em Administração, 9(2), 48-69.

Chell, E. (2011). Introdução e visão geral sobre o empreendedor e o processo de empreendedorismo. In: Ateljevic, J. \& Page, S. J.; Almeida, M. V. Turismo e empreendedorismo. Rio de Janeiro: Elsevier.

Dencker, A. F. M. (2007). Pesquisa em Turismo: planejamento, métodos e técnicas. 9. ed. São Paulo: Futura.

Ferreira, J. M. \& Nogueira, E. E. S. (2013). Mulheres e suas Histórias: razão, sensibilidade e subjetividade no Empreendedorismo Feminino. Revista de Administração Contemporânea, 17(4), 398-417.

Gastal, S. \& Moesch, M. M. (2007). Turismo, políticas públicas e cidadania. São Paulo: Aleph.

GEM. Global Entrepreneurship Monitor. (2010). Empreendedorismo no Brasil. Relatório Nacional. Curitiba: IBPQ.

Gil, A. C. (2008). Métodos e técnicas de pesquisa social. São Paulo: Atlas.

Gomes, A. F. (2006). Mulheres empreendedoras. Vitória da Conquista - BA: UESB.

Gouvêa, A. B. C. T., Silveira, A. \& Machado, H. P. V. (2013). Mulheres Empreendedoras: compreensões do empreendedorismo e do exercício do papel desempenhado por homens e mulheres em organizações. Revista de Empreendedorismo e Gestão de Pequenas Empresas, 2(2), 32-54.

Hisrich, R. D.; Peters, M. P. \& Shepherd, D. A. (2014). Empreendedorismo. 9 ed. Porto Alegre: Bookman.

IBGE, Instituto Brasileiro de Geografia e Estatística (2015). Pesquisa Mensal de Serviços. Recuperado em 10 de dezembro, 2015, de http://www.ibge.gov.br/home/estatistica/indicadores/servicos/pms/

IBGE, Instituto Brasileiro de Geografia e Estatística (2016). Cidades. Recuperado em 10 de junho, 2016, de http://cidades.ibge.gov.br/xtras/home.php 
IBGE, Instituto Brasileiro de Geografia e Estatística (2014). Estatística de gênero: uma análise dos resultados do censo demográfico - 2014. Recuperado em 11 de abril, 2016, de http://www.ibge.gov.br/apps/snig/v1/?loc=0

IBGE, Instituto Brasileiro de Geografia e Estatística (2016). Censo Demográfico 2010: Características urbanísticas do entorno dos domicílios. Recuperado em 11 de abril, 2016, de http://www.ibge.gov.br/home/estatistica/populacao/censo2010/entorno/default_entorno.shtm

Maders, A. M. \& Angelin, R. (2010). A construção da equidade nas relações de gênero e o movimento feminista no Brasil: avanços e desafios. Cadernos de Direito, 10(19), 91-115.

Melhado, J. P., Plaster, J. \& Yoong, P. S. Empreendedores brasileiros: perfis e percepções, 2013. Recuperado em 10 de agosto, 2015, de http://www.cref14.org.br/documentos_download/empreendedores.pdf

Moesch, M. M. (2000). A produção do saber turístico. São Paulo: Contexto.

Natividade, D. R. (2009). Empreendedorismo feminino no Brasil: políticas públicas sob análise. Revista de Administração Pública, 43(1), 231-56.

Nissan, E., Carrasco, I. \& Y Castaño, M. (2012). Women Entrepreneurship, Innovation and Internationalization. In: Galindo, M., \& Ribeiro, D. (eds.), Women's Entrepreneurship and Economics. New Perspectives, Practices and Policies. p. 125-142.

Nogami, V. K. C., Medeiros, J. \& Faia, V. S. (2014). Análise da evolução da atividade empreendedora no Brasil de acordo com o Global Entrepreneurship Monitor (GEM) entre os anos de 2000 e 2013. Revista de Empreendedorismo e Gestão de Pequenas Empresas, 3(3), $31-76$.

OMT, Organização Mundial do Turismo. (2001). Introdução ao turismo. São Paulo: Roca.

Oliveira, K. B., Lopes, G. S. C., Watanabe, M. \& Yamaguchi, C. K. (2015). Duarte, R. Estudo do empoderamento na perspectiva das mulheres. Revista Pretexto, 16(4), 82-99.

Paiva, M. G. M. (1995). Sociologia do turismo. Campinas, SP: Papirus.

Peeters, L. W. J. \& Ateljevic, I. (2011). A ligação do empoderamento e do empreendedorismo feminino: processo de inovação social. In: Ateljevic, J., Page, S. J., \& Almeida, M. V. Turismo e empreendedorismo. Rio de Janeiro: Elsevier.

Rodrigues, R. B., Melo, M. C. O. L. \& Lopes, A. L. M. (2016). Gênero Feminino no Empreendedorismo de Sucesso em Minas Gerais: Estudo de Casos. Organizações em contexto, 12(23), 143-172.

Ruschmann, D. V. M. \& Solha, K. T. (2004). Turismo: uma visão empresarial. Barueri-SP: Manole.

SEBRAE, Serviço Brasileiro de Apoio às Micro e Pequenas Empresas. (2014). Mulher de negócios: empreendedorismo feminino em pauta. Campo Grande: SEBRAE.

Sehgal, A. (2014). Synergy between Women Entrepreneurship and Empowerment. II TM Journal of Management and IT, 5(2), 26-31. 
Silva, A. C. C. J., Furtado, J. H. \& Zanini, R. R. (2015). Evolução do empreendedorismo no Brasil baseada nos indicadores do Global Entrepreneurship Monitor (GEM). Revista Produção Online, 15(2), 758-780.

Scott, J. W. (1990). Gênero: uma categoria útil de análise histórica. Educação e Sociedade, $16(2), 5-22$.

Tonelli, M. J. \& Andreassi, T. (2013). Mulheres empreendedoras. GV Executivo, 12(1), 50-53.

Vieira, J. A. (2005). A Identidade da mulher moderna. Delta, 2, 207-238.

WTO. World Tourism Organization - UNWTO (2010). Global report on women in tourism: Preliminary findings. Recuperado em 10 de abril, 2016, de http://www2.unwto.org/sites/all/files/pdf/folleto_globarl_report.pdf 